\title{
Investigation of Broken Rotor Bar Faults in Three-Phase Squirrel-Cage Induction Motors
}

\author{
Ying Xie \\ Harbin University of Science and Technology, \\ China
}

\section{Introduction}

It is well understood that squirrel-cage induction motors are rugged, reliable, cheap, and thus widely used in industrial and manufacturing processes. However, electrical and mechanical faults pose a particular challenge to the industry and end users which often interrupts the productivity and requires maintenance. In literature, rotor faults have been shown to account for a large portion of induction motor failures, sometimes they are the single biggest cause of failure in the field. Rotor bar faults generally arise from repeated operating stresses which can be electrical, mechanical, thermal or environmental by nature. The causes of rotor bar and end-ring breakage include: (a) magnetic stresses caused by electromagnetic forces, (b) thermal stresses due to abnormal operating duty, including overload and unbalance, (c) inadequate casting, fabrication procedures or overloading, (d) contamination and abrasion of rotor because of poor operating conditions, (e) lack of maintenance. Most failures will increase the current and stress in the adjacent bars, progressively deteriorating the rotor part and degrading the motor's overall performance. Without doubt, it is of great importance to appreciate the mechanisms and characteristic changes of broken bar faults. Furthermore, an online fault diagnostic system is highly desired to meet the reliability requirements, as well as reducing the costs of maintenance and increasing field efficiency.

\section{Broken bar faults in squirrel-cage induction motors}

During the past twenty years, there have been continuing efforts at studying and diagnosing faults in induction motors and, in particular, substantial research work is devoted to induction motor bar breakages and the development of non-intrusive diagnostic techniques (Elkasabgy et al., 1992; Bellini et al., 2001; Said et al., 2000). Some research work was based on the finite element (FE) techniques (Mohammed et al., 2006; Mirafzal \& Demerdash, 2004; ying xie, 2009; Sprooten \& Maun, 2009; Bentounsi \& Nicolas, 1988; ying xie, 2010), and more information may be retrieved for diagnostic purpose. It is well established to use line currents as an indicative parameter (Kliman et al., 1988) which can provide insight into the basis of a non-invasive condition monitoring system for the early detection. Other research effort has been focused on the motor current signature analysis (Costa, et al., 2004; Walliser \& Landy, 1994; Bacha et al., 2004; Thomson \& Fenger, 2001) in order to detect electrical and mechanical faults in induction motors. Another issue reported in literature is the 
temperature-rise-related failure which has also received much research attention. For example, some research has been conducted on totally enclosed fan-cooled (TEFC) induction motors by thermal sensitivity analysis (Mueller et al., 1995; Boglietti et al., 2005; Staton et al., 2005; ). In this reference, the thermal design issues were reviewed and optimisation design algorithms were also developed. References (Alberti \& Bianchi, 2008) propose a coupled thermal-magnetic analysis of an induction motor with the primary goal of achieving a rapid and accurate prediction of the IM performance. The heating problem of a motor when one of rotor bars is totally broken was simulated in some papers (Casimir et al., 2004); and some papers investigated the heating characteristics and heat distribution of the motor with healthy and broken rotors (Cho et al., 1992; Lopez-Fdez et al., 1999; Antal \& Zawilak, 2005). Indeed, there are some technical challenges when analysing electrical motor thermal fields under broken-bar fault conditions although many papers have covered this area of research. In particular, there is little work on the influence of breaking bars on the temperature-rise of electrical motors using quantitative methods. This chapter will bridge the gap. This chapter is also set out to discuss early diagnostic techniques to identify the faults.

\section{Experimental setup}

A dedicated experimental test bench has been designed for testing squirrel-cage induction motor faults. One stator and three originally identical rotors have been employed to study the behaviours of the induction motor with or without broken bars. Prior to the start of the testing process, two out of the three rotors are damaged deliberately by drilling holes in the bars on all their depth and used with the same stator to ensure the testing accuracy. The healthy rotor is considered here as a reference. The laboratory test setup and broken bar rotors are shown in Fig. 1.

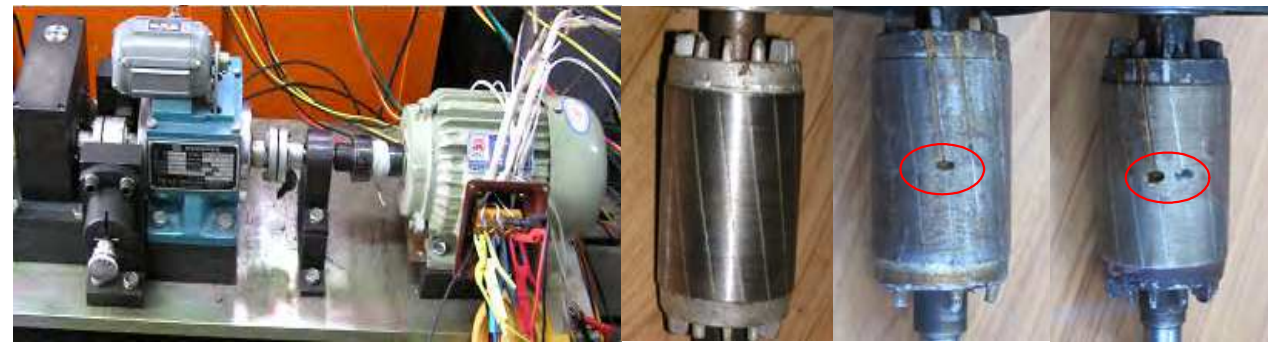

Fig. 1. The experimental setup and the three rotors.

\section{Search coil and voltage detection techniques}

The measured value of air-gap flux density can be obtained by the search coil technology, and it can be applied to motors operating under different loads. The search coil is inserted around the stator tooth tip, as is shown in Fig. 2. The value of air-gap flux density is obtained by analyzing the induced voltage waveform in the coil, which could help to detect the presence of broken bars.

The technique uses a search coil mounted on the internal stator tooth tip and the analysis of the induced voltage waveform to detect the presence of broken bars. The induced voltage in search coil is given by 


$$
E_{i}=2 B_{i} L v=2 \frac{B_{i m}}{\sqrt{2}} L \frac{\Pi D n_{s}}{60}
$$

where $B_{i m}$ is the amplitude of the fundamental component and theith harmonic component, $E_{i}$ is the effective value of voltage induced by the fundamental air-gap flux and the $i$ th harmonic air-gap flux, $\mathrm{D}$ is the inner diameter of the stator core, $\mathrm{n}_{\mathrm{s}}$ is the synchronous speed, $\mathrm{L}$ is the effective length of the search coil.

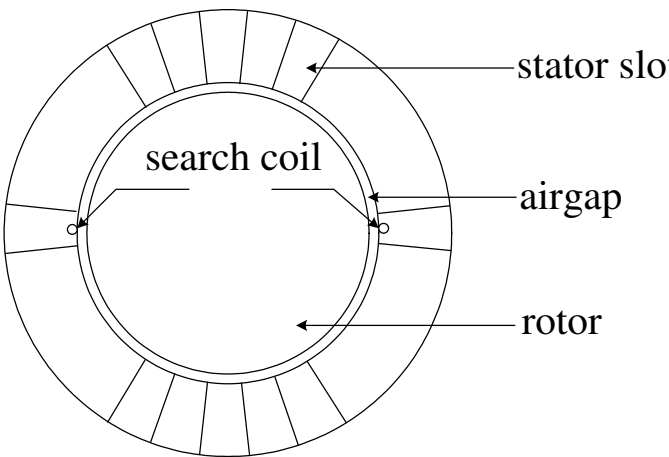

(a)

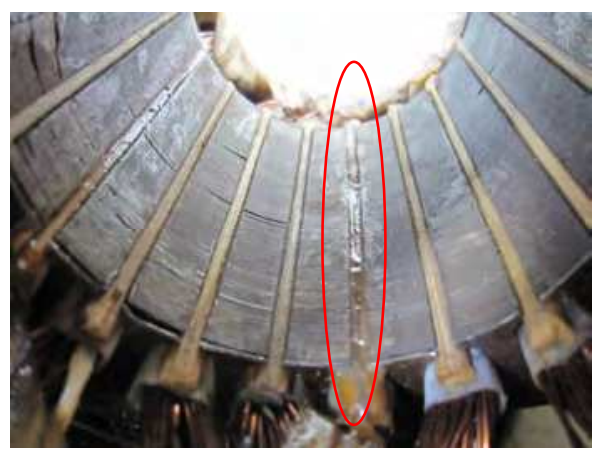

(b)

Fig. 2. The search coil positions. (a) The sketch map of the search coil technology, (b) measuring position in the experiment

Under rated load conditions, the air-gap field is dissymmetrical in the case of broken bars and the harmonic components of air-gap flux density vary significantly. The third harmonic components for the case of a faulty motor are pronouncedly higher and ripple more severely than that of the healthy condition. The appearance of a faulty third harmonic component is clearly an effective method of detecting broken bars, and the test results showed the faulty third harmonic component of air-gap flux density becomes more significant as the number of the broken bars is increased. The results of the first and third harmonic of the air-gap flux density are shown in Table I for the sample simulation and experiment. (The first harmonics for the case of normal and abnormal conditions from experiment are also fluctuated with time, and the maximal values are listed in the Table 1.) (Weili Li et al., 2007)

\begin{tabular}{|c|c|c|c|c|}
\hline & \multicolumn{2}{|c|}{$1^{\text {th }}$ harmonic $(\mathrm{t}=1 \mathrm{~s})$} & \multicolumn{2}{c|}{$3^{\text {th }}$ harmonic $(\mathrm{t}=1 \mathrm{~s})$} \\
\hline & Experimental & Simulated & $\begin{array}{c}\text { Experimental value } \\
\text { range }\end{array}$ & Simulated \\
\hline Healthy bars & $0.6534(\mathrm{~T})$ & $0.6414(\mathrm{~T})$ & $0.0008-0.0168(\mathrm{~T})$ & $0.0113(\mathrm{~T})$ \\
\hline A broken bar & $0.6601(\mathrm{~T})$ & $0.6437(\mathrm{~T})$ & $0.0034-0.0386(\mathrm{~T})$ & $0.0216(\mathrm{~T})$ \\
\hline $\begin{array}{c}\text { Two adjacent broken } \\
\text { bars }\end{array}$ & $0.6887(\mathrm{~T})$ & $0.6480(\mathrm{~T})$ & $0.0042-0.0848(\mathrm{~T})$ & $0.0391(\mathrm{~T})$ \\
\hline
\end{tabular}

Table 1. The fundamental and third harmonic component of air gap flux density comparison for simulation and experiment at rated load 


\section{Influence of broken bar faults on the magnetic field distribution}

The following assumptions have been made in the solution procedure.

- Displacement current is neglected because the frequency of the source is very low.

- The rotor bars are insulated from the rotor core, and there is no direct electrical contact between the rotor bars and the rotor core.

- The leakage on the outer surface of the stator and the inner surface of the rotor is neglected.

- The 2-D domain is considered, and the magnetic vector potential and the current density have only the axial $\mathrm{z}$ component.

The 2-D model of the motor is employed, and the fundamental equation describing the space and time variations of the vector potential has the following form.

$$
\left\{\begin{array}{l}
\mathrm{D}: \frac{\partial}{\partial \mathrm{x}}\left(\frac{1}{\mu} \frac{\partial \mathrm{A}_{\mathrm{z}}}{\partial \mathrm{x}}\right)+\frac{\partial}{\partial \mathrm{y}}\left(\frac{1}{\mu} \frac{\partial \mathrm{A}_{\mathrm{z}}}{\partial \mathrm{y}}\right)=-\mathrm{J}_{\mathrm{z}}+\sigma \frac{\partial \mathrm{A}_{\mathrm{z}}}{\partial \mathrm{t}} \\
\Gamma_{1}: \mathrm{A}_{\mathrm{z}}=0
\end{array}\right.
$$

where $\mathrm{D}$ is the region of analysis, $\Gamma_{1}$ is the outside circumferential of the stator and inside circumferential of the rotor (the Dirichlet boundary conditions), $\mathrm{J}_{\mathrm{z}}$ is current density, $\sigma$ is the conductivity of the conductors, $\mathrm{A}_{\mathrm{z}}$ is magnetic vector potential, $\mu$ is the permeability of the material (Ning Yuquan,2002; Tang Yunqiu,1998; Yan Dengjun et al., 2003; Bangura \& Demerdash 1999; Gao Jingde et al., 1993; ying xie, 2009).

The distribution of magnetic field of the motor for the case of no broken bars is symmetrical under the rated load conditions and the locked rotor conditions, while the symmetry of magnetic field distribution is distorted in the case of broken bars. Samples of flux density distributions across the cross-section of the motor are shown in Fig. 3-4. From them, we know that the magnetic saturation around the broken bars is more severe than that of the rated load. In addition to changes in the broken bar regions, the field distributions at other positions in the stator and rotor core are also distorted and increased to some extent, while these are less significant in the case of the rated load.

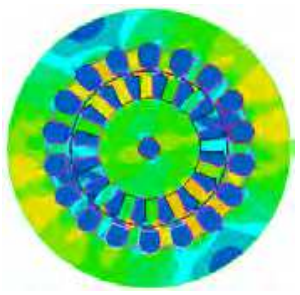

(a)

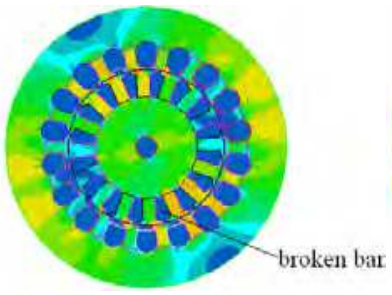

(b)

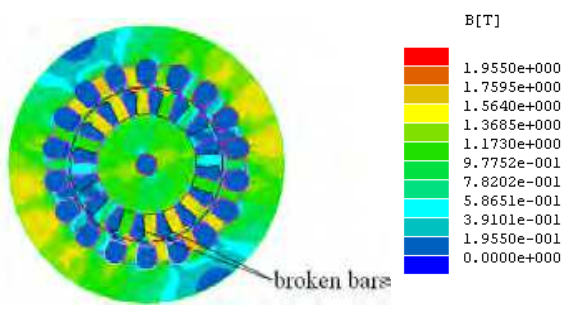

(c)

Fig. 3. The flux density distribution at rated load. (a) healthy rotor, (b) one broken bar, (c) two bar broken 


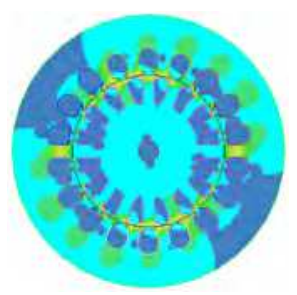

(a)

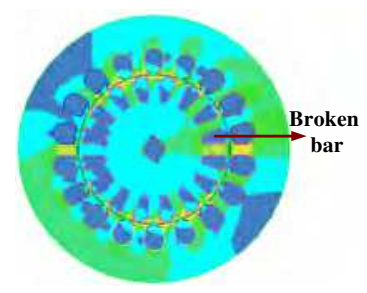

(b)

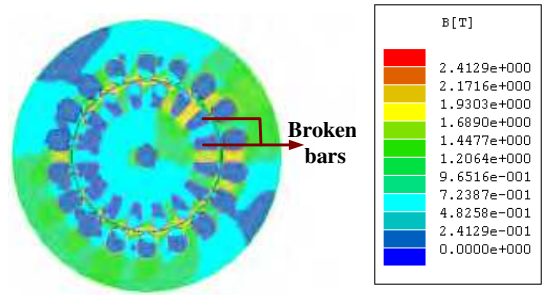

(c)

Fig. 4. The flux density distribution at standstill. (a) healthy rotor, (b) one broken bar fault, (c) two bar broken fault

In order to study the higher degree of magnetic saturation around broken bars, the magnetic flux density waveforms of A, B and C points are given in this paper. The three different positions which are adjacent to broken bars in the stator and rotor core are shown in Fig.5.
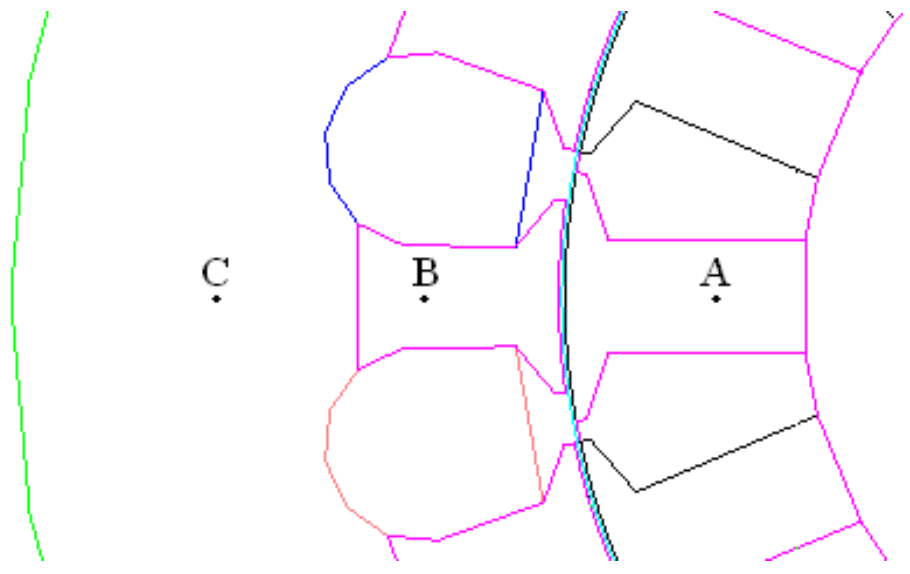

Fig. 5. The three different positions in the stator and rotor core.

The typical time variation flux density waveforms of $\mathrm{x}$ and $\mathrm{y}$ component at positions $\mathrm{A}$. $\mathrm{B}$ and $C$ are shown in Fig.6. One can notice that the flux density change is periodic and calm on the condition of healthy rotor, however, the flux density fluctuations with time after broken bar fault. A comparison of flux density plot between the healthy cage and the broken bars fault demonstrates the harmonic components of the flux density on the different positions for broken bars are greater than those for healthy rotor. To specify this statement, the magnetic flux frequency spectrum at selected position B is analyzed by harmonic analysis procedure, see Fig.7. From it we can know that the flux density contains higher spatial harmonics in the case of broken bars. 

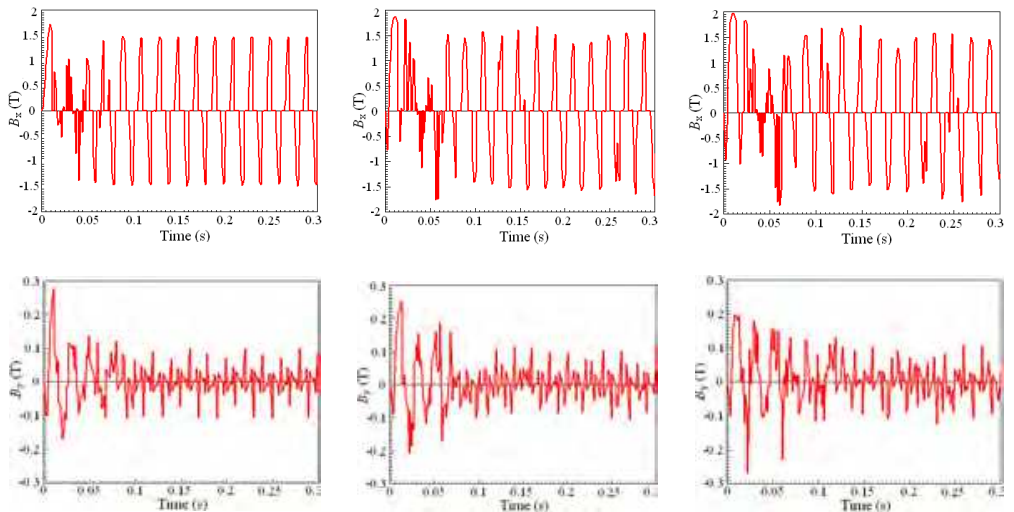

(a)
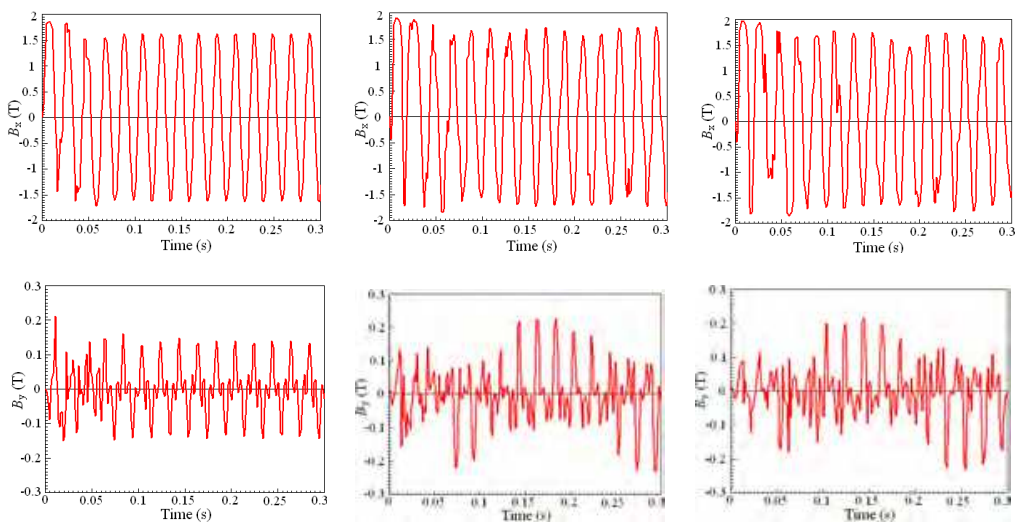

(b)
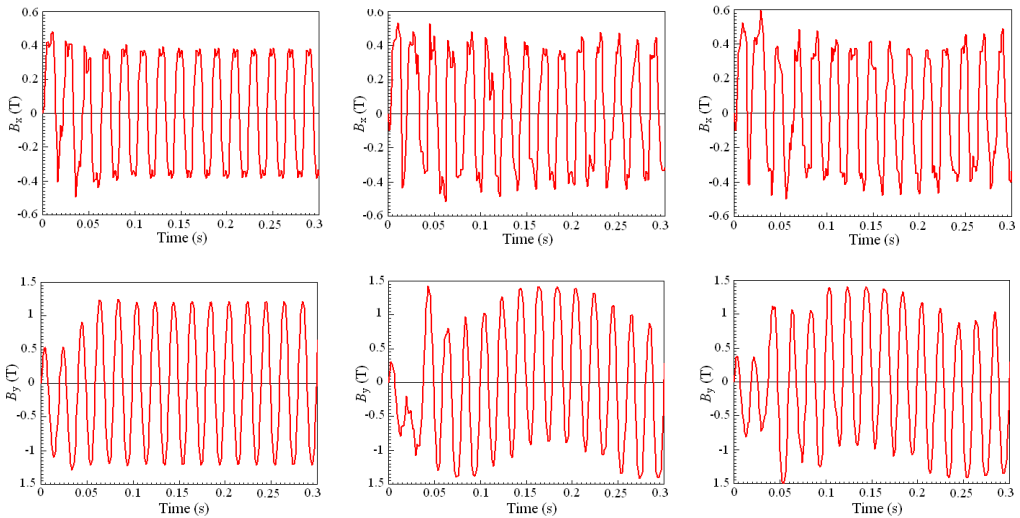

(c)

Fig. 6. Typical time variation of flux density waveform of $x$ and $y$ component at rated load with and without broken bar fault. (a) positions A, (b) positions B , (c) positions C (ying xie,2009) 

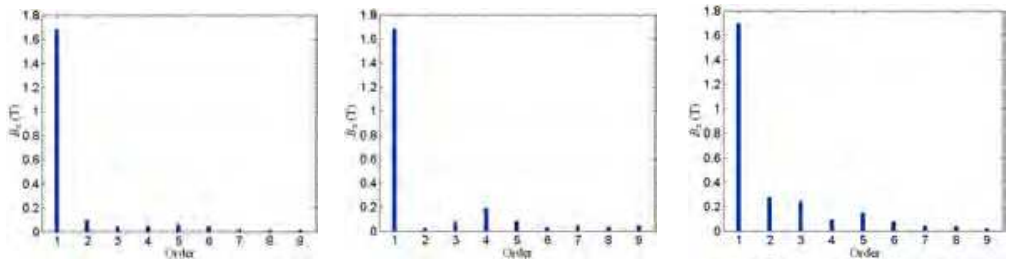

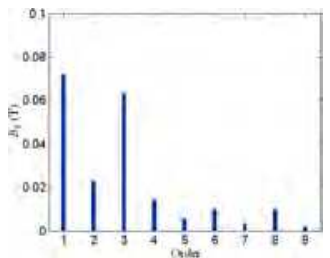

(a)

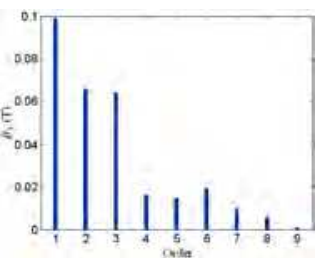

(b)

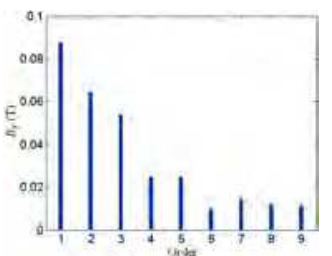

(c)

Fig. 7. The flux density frequency spectrum at position B at rated load. (a) healthy motor cage, (b) a one-broken bar fault, (c) a continuous two-broken-bar

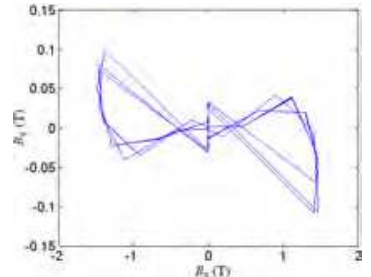

(a)

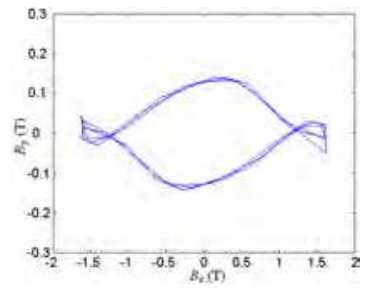

(a)

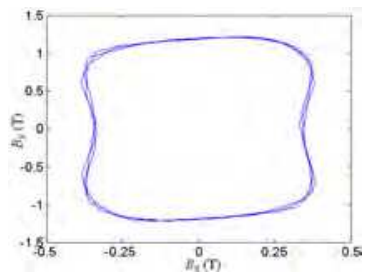

(a)

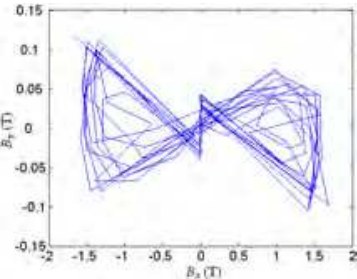

(b)

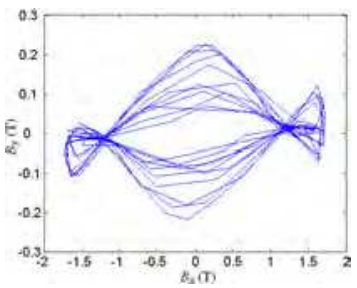

(b)

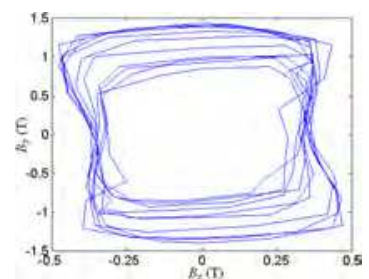

(b)

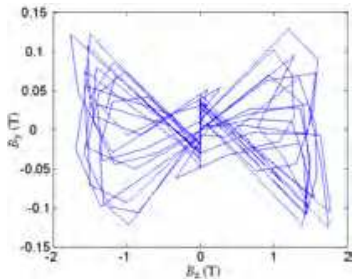

(c)

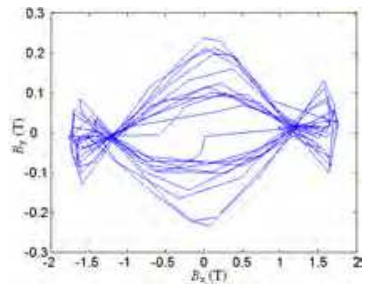

(c)

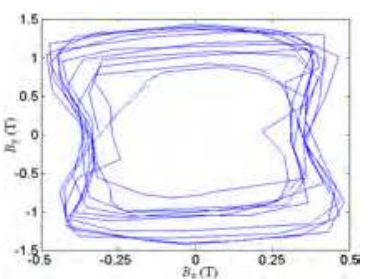

(c)

Fig. 8. Elliptical flux density vector waveform at position A, B and C at rated load. (a) healthy motor cage, (b) a one-broken bar fault, (c) a continuous two-broken-bar 
Fig. 8 is the elliptical flux density at positions A, B and C, from it, we can see that the trace of elliptical flux density in case of healthy motor is nearly the same; however it is disorderly and unsystematic when broken bar fault happened. All radii of elliptical flux density vector for broken bars are greater than those for the healthy case, which is due to the local heavy magnetic saturation appearing in the vicinity of the bar breakages.

\section{Operation characteristics of induction motors with broken bar fault}

The effect of the broken bar in three-phase cage-rotor induction motors on the motor's operating performances is investigated under both the rated load conditions and the locked rotor conditions. A 2-D Time-Stepping Coupled Finite Element Method (TSCFEM) is employed for predictive characterization of rotor broken bars in induction motors. Simulation results based on detailed theoretical analysis are confirmed by the experimental results.

\subsection{Stator currents}

In the generalized rotating field theory, a backward-rotating field can be produced by the broken rotor bar faults and then lower sideband components in the stator current spectrum at double slip-frequency is introduced. Figs. 9-10 show experimental and simulated transient phase currents at rated load. One can notice that the amplitude of stator current fluctuations with time compared to that in the healthy cage. However, while the tests are performed at standstill, the fault-specific sideband components of stator currents do not appear near the fundamental component. Therefore, the stator current for healthy rotor at standstill is very similar to that for faulty rotors. Figs. 11-12 show experimental and simulated stator currents at standstill with healthy and faulty rotors for comparison.

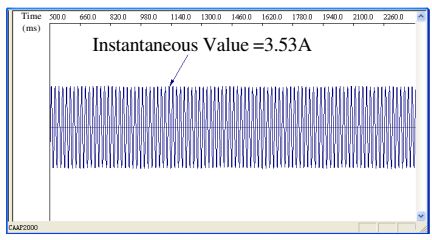

(a)

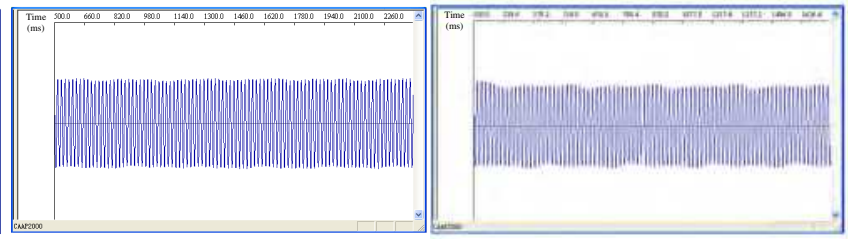

(b)

(c)

Fig. 9. The experimental stator current profile at rated load. (a) healthy rotor, (b) one broken bar, (c) two broken bars

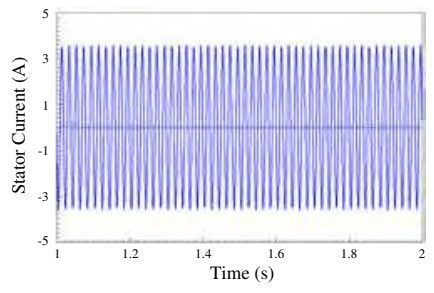

(a)

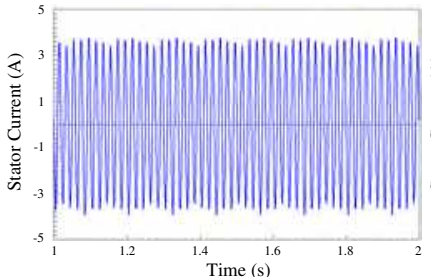

(b)

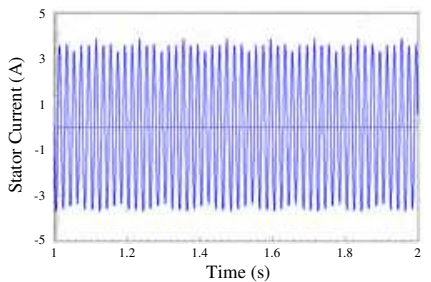

(c)

Fig. 10. The simulated stator current profile at rated load. (a) healthy rotor, (b) one broken bar, (c) two broken bars (ying xie 2009) 


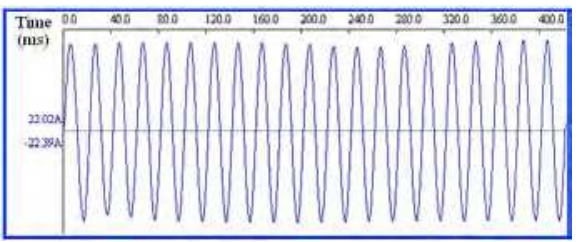

(a)

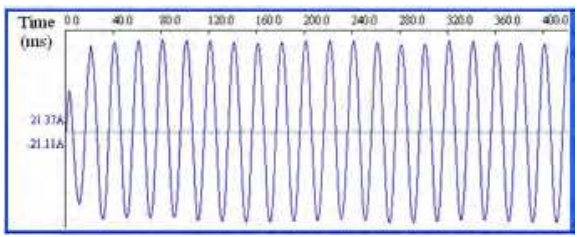

(b)

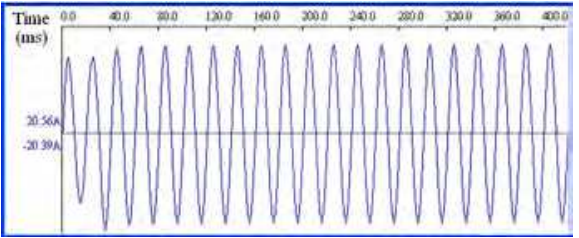

(c)

Fig. 11. The experimental stator current waveforms at standstill. (a) healthy rotor, (b) one broken bar, (c) two broken bars

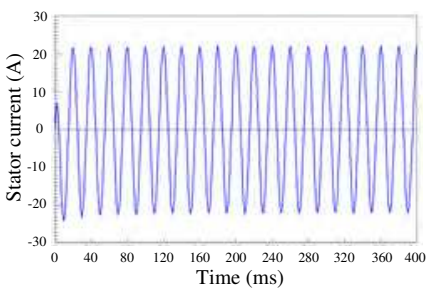

(a)

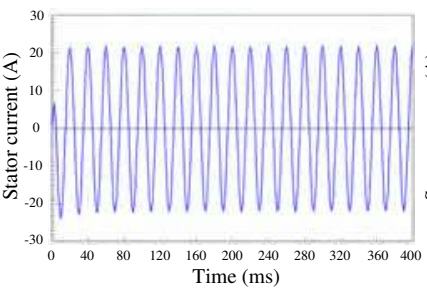

(b)

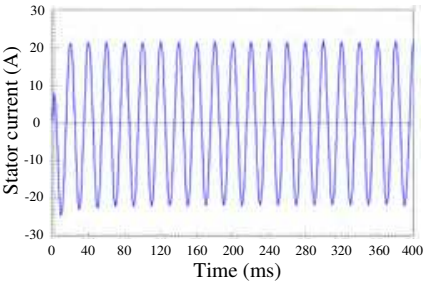

(c)

Fig. 12. Simulated stator current waveforms at standstill. (a) healthy rotor, (b) one broken bar, (c) two broken bars

\subsection{Rotor-bar currents}

When the rotor is rotating, each rotor bar passes every stator slot, so that each bar will be equally influenced by all the stator-driven flux waves, and all the currents of the rotor bars at rated load are sensibly uniform around the rotor periphery. Fig. 13 shows rotor-bar currents at rated load. It can be seen that the amplitude of the adjacent bars has the highest value in the bars next to the broken ones, this explains why and how bar damage propagates. The currents in bars far away from the broken bars remain almost the same. 


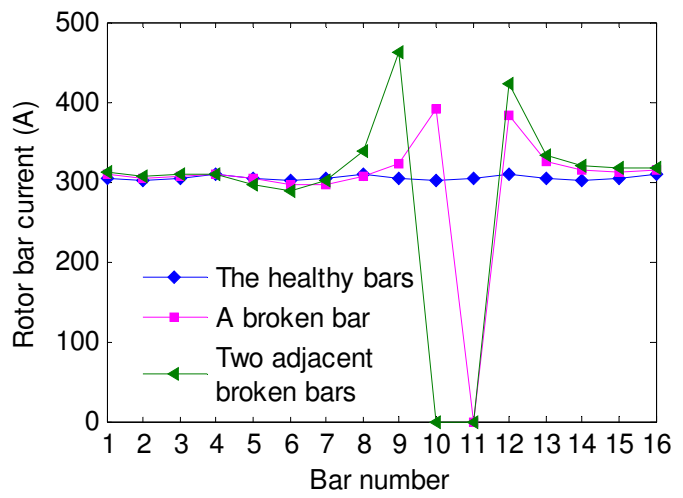

Fig. 13. The simulated rotor bar current at rated load.

At standstill, however, the current amplitude of the trouble-free rotor varies with position around the rotor periphery and is not equal, which is different from the rated load. The variation of the rotor current in fault at standstill in accordance with it at rated load and the current amplitude at standstill increases more serious, which can be seen from Figure 14.

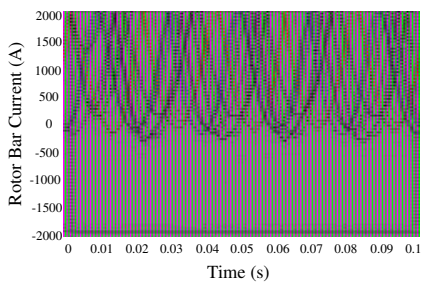

(a)

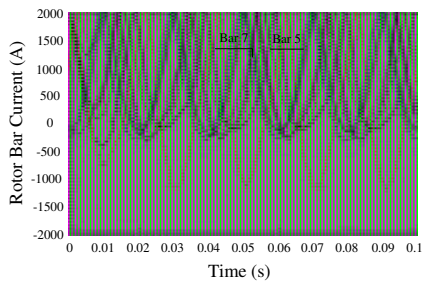

(b)

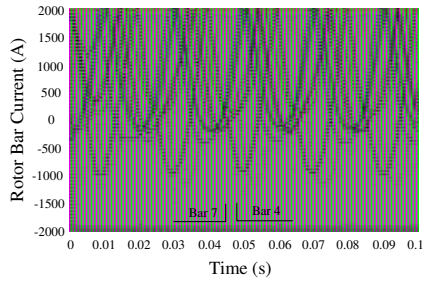

(c)

Fig. 14. The simulated rotor current at standstill: (a) healthy cage, (b) one broken bar, (c) two broken bars

\subsection{Magnetic force on the rotor}

There have been a variety of methods for calculating local magnetic forces, i.e. the methods based on the virtual work principle, on the Maxwell stresses or on the forces acting on equivalent sources (magnetizing current or magnetic charges). In this section, the method of virtual work is employed in the process of the magnetic force calculation. There is the magnetic force on the rotor bars because of the induced current in the bars. In the twodimensional magnetic field, the magnetic force can be expressed as follows.

$$
\mathrm{f}_{\mathrm{k}}=\iint_{S_{\mathrm{k}}} \mathrm{Jl} \times \mathrm{B}_{\mathrm{k}} \cdot \mathrm{dS}
$$

where $\mathrm{k}$ is unit number, $\mathrm{f}_{\mathrm{k}}$ is the magnetic force of the unit $\mathrm{k}, \mathrm{S}_{\mathrm{k}}$ is the area of the unit $\mathrm{k}, \mathrm{J}$ is the induced current density on the rotor bars, 1 is the length of the bars, $B_{k}$ is the magnetic flux density of the unit $\mathrm{k}$. The magnetic force corresponding to Eq.3 may be simplified, and it becomes 


$$
\left\{\begin{array}{l}
\mathrm{f}_{\mathrm{t}, \mathrm{k}}=\mathrm{B}_{\mathrm{n}, \mathrm{k}} \mathrm{S}_{\mathrm{k}} \mathrm{Jl} \\
\mathrm{f}_{\mathrm{n}, \mathrm{k}}=\mathrm{B}_{\mathrm{t}, \mathrm{k}} \mathrm{S}_{\mathrm{k}} \mathrm{Jl}
\end{array}\right.
$$

where $f_{t, k}, f_{n, k}$ are the tangential component and the normal component of magnetic force, $\mathrm{B}_{\mathrm{t}, \mathrm{k}}$ and $\mathrm{B}_{\mathrm{n}, \mathrm{k}}$ are the tangential component and the normal component of magnetic flux density respectively. Therefore, the magnetic force of the unit $\mathrm{k}$ is

$$
f_{k}=i f_{t, k}+j f_{n, k}
$$

In this section, the magnetic force distribution on the rotor bar at rated load and at standstill is computed, and the position of broken bars is shown in the Fig.15. The magnetic force distributions on the rotor bar at rated load and at standstill are computed by the FE method and the results are shown in the Fig. 16-17 for comparison. It can be noticed that the bars with the highest magnetic force are those immediately adjacent to the broken bars, whether the motor operating under rated load conditions or standstill conditions. Consequently, such non-uniform distribution of the force inevitably leads to excessive mechanical stress in the bars, and the bars would become more susceptible to additional wearing and eventual breaking.

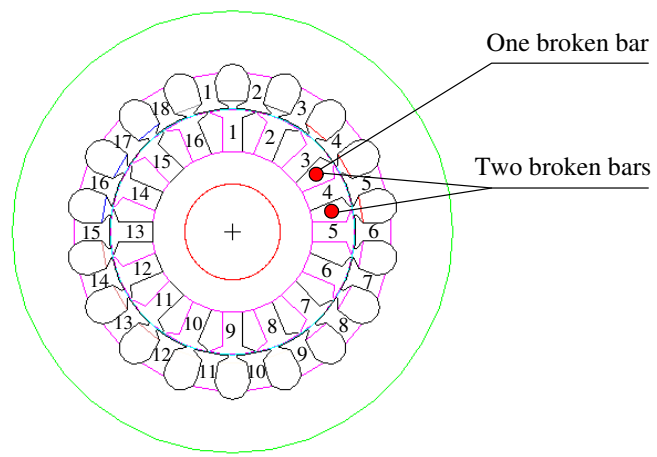

Fig. 15. The serial number of the stator tooth and rotor tooth.

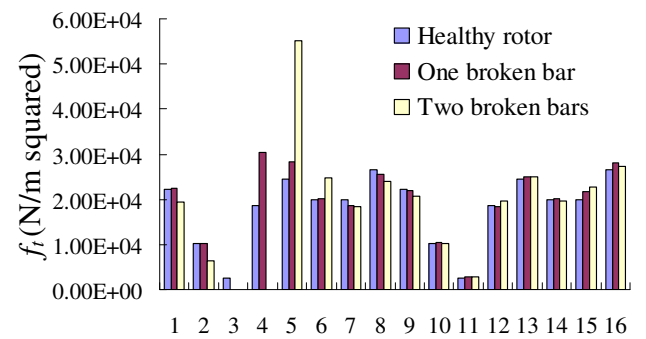

The serial number of rotor bar

(a)

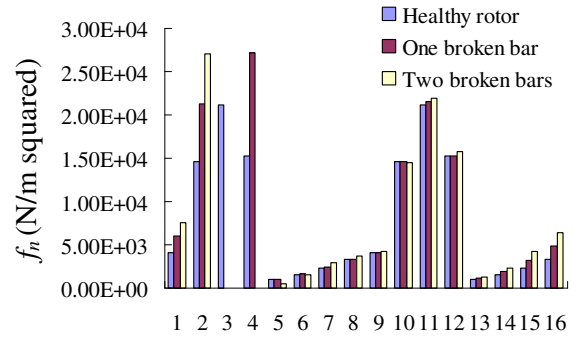

The serial number rotor bar

(b)

Fig. 16. The magnetic force distribution of every rotor bar at rated load. (a)Tangential component, (b) Normal component 


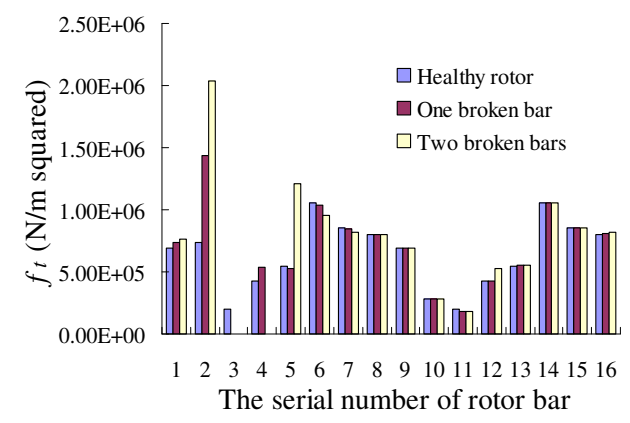

(a)

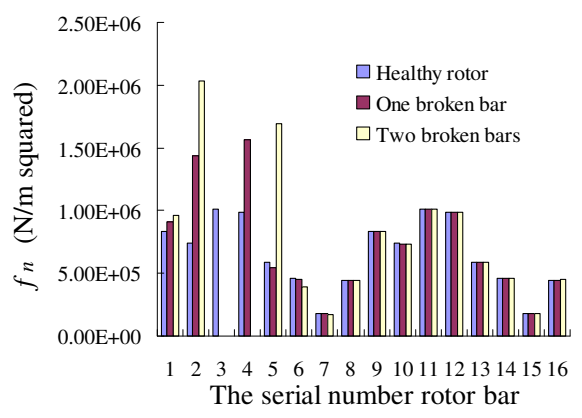

(b)

Fig. 17. The magnetic force distribution of every rotor bar at locked rotor. (a)Tangential component, (b) Normal component

\subsection{Torques}

The torque variation at rated load is given in Fig.18, and the torque is smooth at no fault, and torque ripple can be observed in faulty conditions. The torque tendency at rotor-locked conditions is different to that at rated load condition, see Fig. 19. The torque waveforms are almost identical. Through further observations, the average torque is reduced at lockedrotor conditions (from 12.28, 11.23 to $10.22 \mathrm{Nm}$, respectively). It becomes clear that the average torque continues to decrease, impacting on the loading capability of the motor.

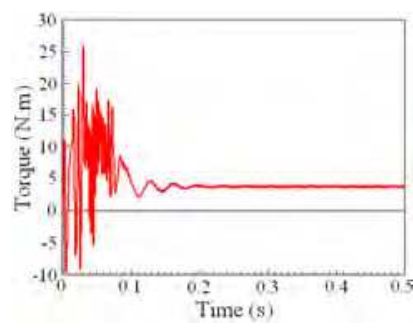

(a)

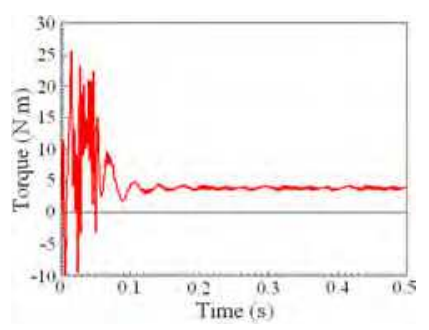

(b)

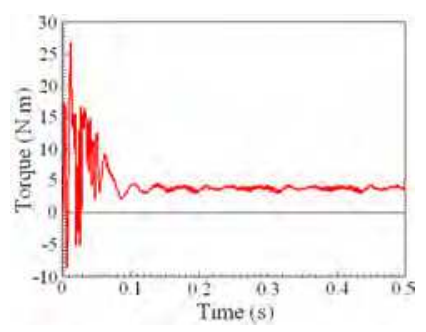

(c)

Fig. 18. The torque at rated load. (a) healthy cage, (b) one broken bar, (c) two broken bars (ying xie, 2009)

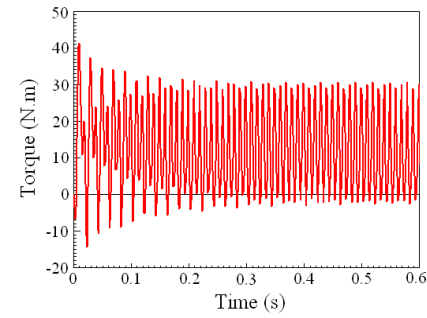

(a)

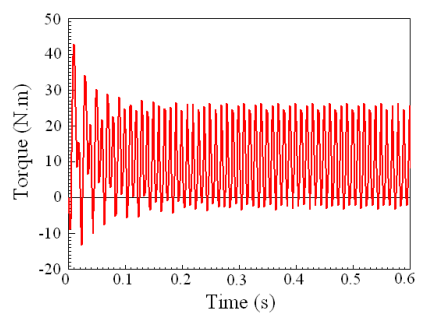

(b)

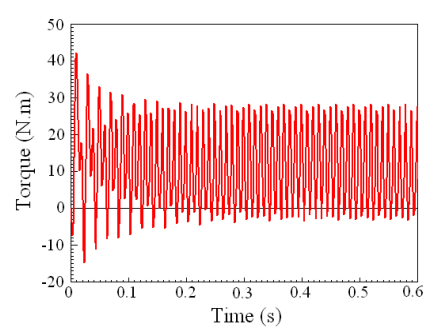

(c)

Fig. 19. The torque at standstill: (a) healthy cage, (b) one broken bar, (c) two broken bars 


\subsection{Core loss of the motor}

The variation of iron core loss at rated load with time is shown in Fig.20. For motor with healthy bars, the core loss of stator is stable under steady state. When broken bars fault happened, the starting core loss of stator is significantly higher than normal motor, and the core loss is fluctuant with time rather than smooth under steady state. The amplification of this distortion is directly related to the number of broken bars, and this was mainly due to deformation of electromagnetic field deduced by broken bars fault, and the magnetic saturation and higher harmonic component around the broken bars.

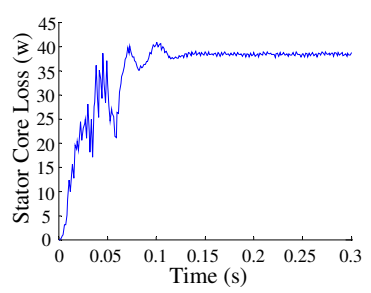

(a)

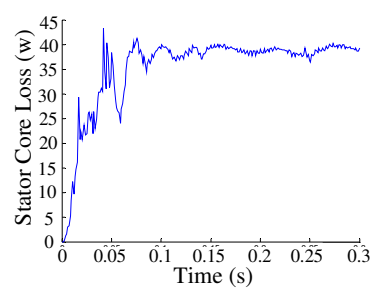

(b)

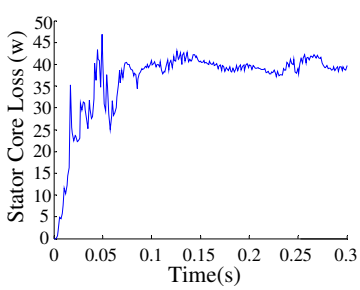

(c)

Fig. 20. Variations of stator core losses versus time before and after broken bars at rated load. (a) healthy motor cage, (b) a one-broken-bar fault, (c) a continuous two-broken- bar (ying xie, 2009)

On figure 21-22, we present the variation of stator and rotor iron core loss with time at locked-rotor for healthy and broken bars faulty condition respectively.

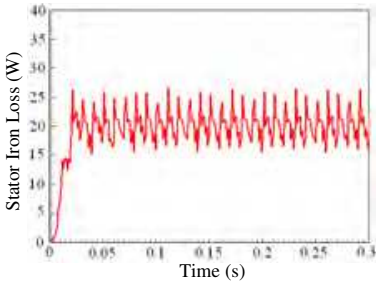

(a)

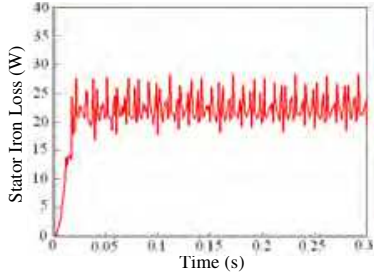

(b)

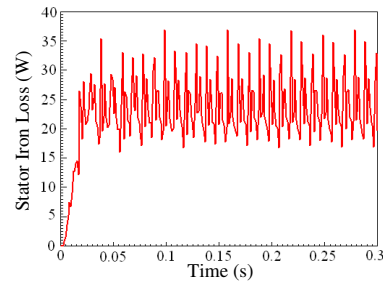

(c)

Fig. 21. Typical time variation of stator core loss at locked rotor. (a) healthy motor cage, (b) a one-broken-bar fault, (c) a continuous two-broken- bars

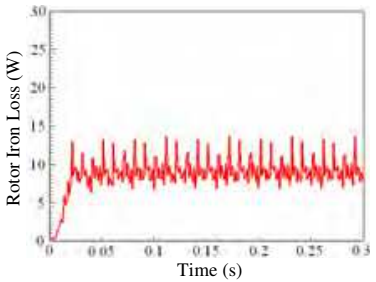

(a)

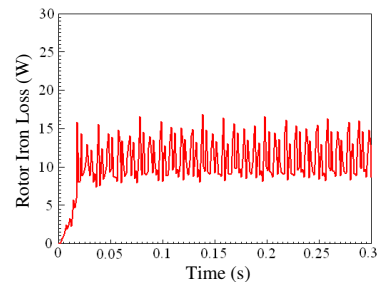

(b)

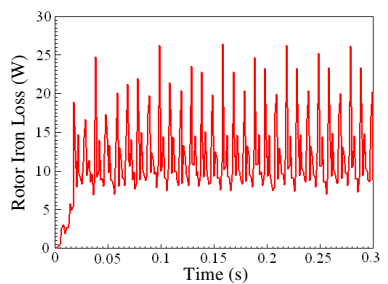

(c)

Fig. 22. Typical time variation of rotor core loss at locked rotor. (a) healthy motor cage, (b) a one-broken-bar fault, (c) a continuous two-broken- bars 
From it we can note the stator and rotor core losses are fluctuant with time whatever the motor is normal or not, which is different from the rated load conditions, for motor with healthy bars, the core loss of stator and rotor is stable under steady state when the motor is operating in the rated load. When broken bars fault happens, the core losses of stator and rotor are significantly higher than normal motor at standstill, and the fluctuation is more intense. In addition, the rotor core losses can not be ignored at standstill.

\section{Influence of broken bar faults on the thermal field distribution}

For TEFC (Totally Enclosed Fan-Cooled) induction motor, the 2-D thermal analysis is well accepted. Then the difficulty in calculating the thermal field is reduced to some extent and the simulation time is beneficially reduced. In terms of the calculation results of electromagnetic field and some empirical formulas, the heat losses can be obtained. The steady temperature distributions of the motor operating at the rated load are calculated shown as Fig.23.

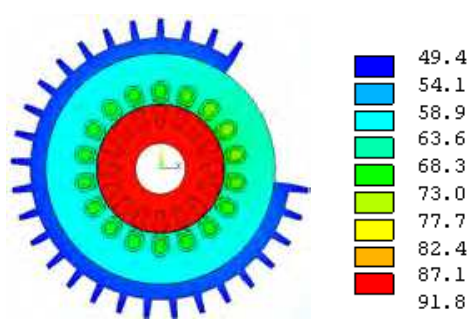

(a)

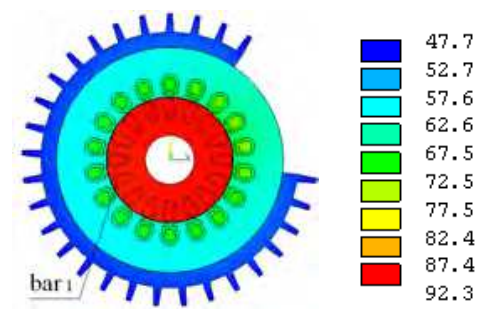

(b)

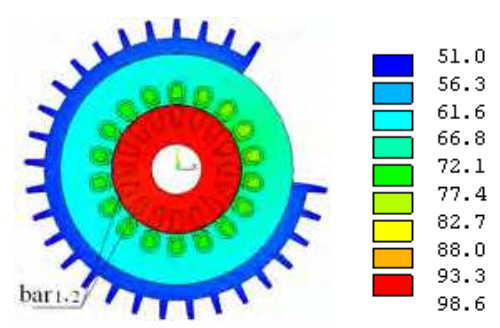

(c)

Fig. 23. Temperature distribution of solving region: (a) healthy motor cage; (b) Bar 1 broken; (c) Bar 1 and Bar 2 broken (ying xie 2010) 
It can be seen that the rotor temperature is highest, and the temperature distribution tendencies of the faulty conditions are similar to that of the motor with healthy rotor. Therefore the broken bar fault has an unobvious influence on the total temperature distribution tendency of the motor.

Fig.24 are the steady rotor temperature distributions of the motor at the above three states. The rotor temperature distribution of the motor with a healthy rotor is not complete symmetry because of the quasi-stationary-state treatment of the air-gap and the incomplete symmetry of the motor house. But the whole rotor solving region is quite small which is due to the large thermal conductivities of the rotor core and rotor bar. It can be found that the lowest temperatures are in the positions of broken bars in the whole rotor solving region from Fig.24 (b) and (c). It indicates that with the increase of the broken bar number, the temperature-rise at the same position of the motor increases. It can be predicted that the temperature-rises of the stator windings and the rotor will increase dramatically in the case of the motor with serious adjacent broken bars fault.

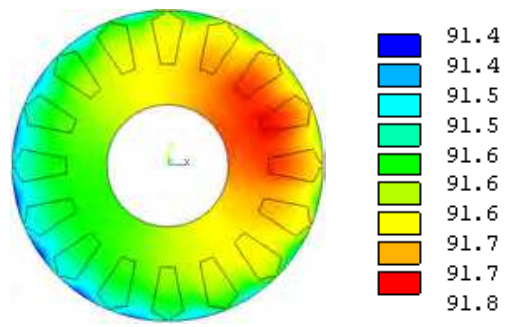

(a)

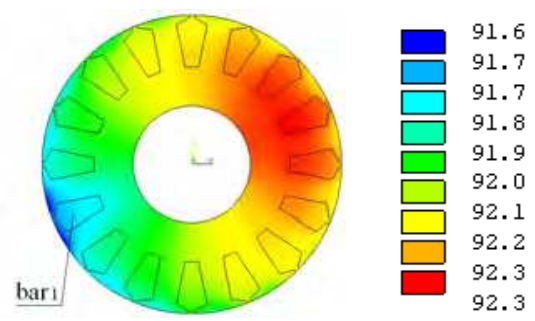

(b)

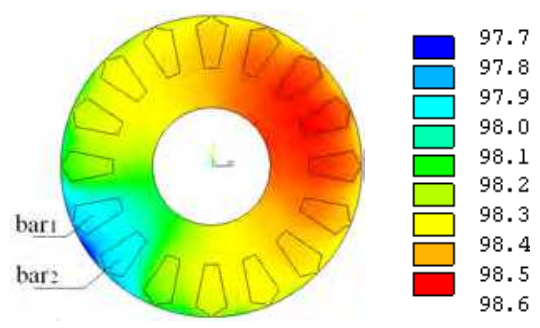

(c)

Fig. 24. Rotor temperature distribution. (a) healthy motor cage, (b) a bar 1 broken, (c) bar 1 and bar 2 broken (ying xie 2010) 
The air-gap temperature distribution along radial is given in Fig. 25. From it the temperature gradient of the air-gap along radial is rather large. The temperature distribution throughout stator slot along radial of the motor cross section is given as Fig. 26.

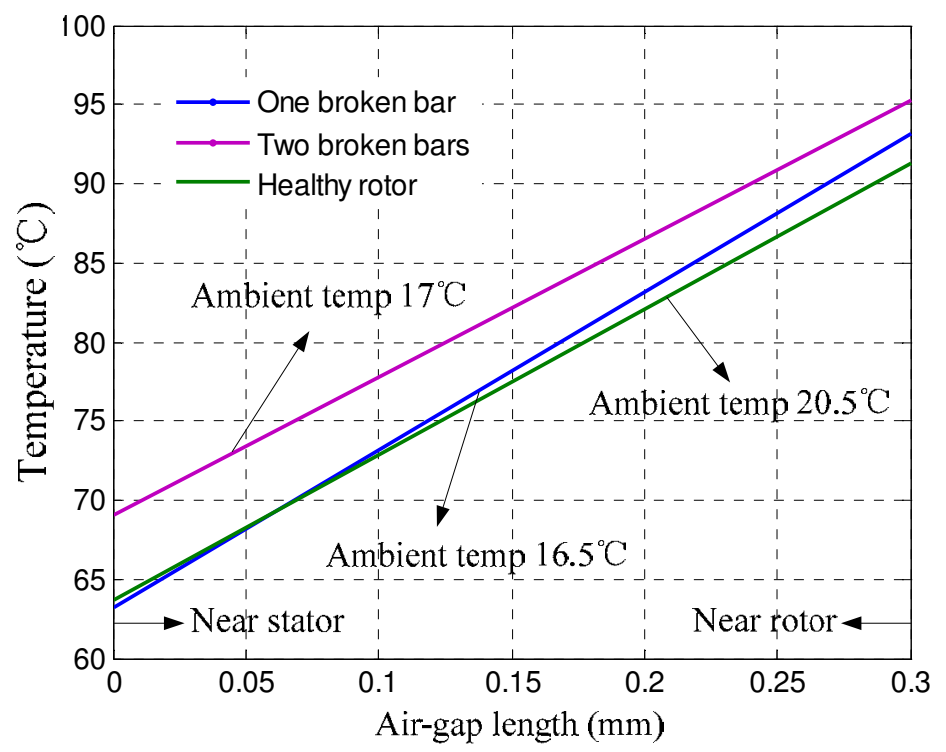

Fig. 25. The air-gap temperature distribution along radial

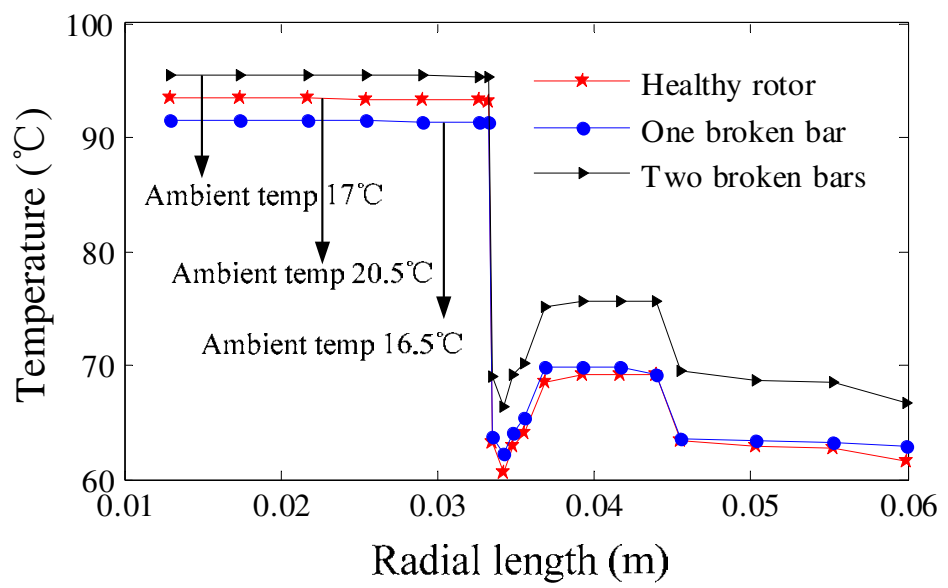

Fig. 26. Temperature distribution throughout radial 


\section{Conclusions}

In this chapter, the application of a Time-Stepping Coupled Finite Element Method for predictive characterization of effects of rotor broken bars has been presented in a comprehensive fashion. The FE analysis has clearly showed that the effect of the broken-bar fault on motor electromagnetic, mechanical performance, and temperature field. Core losses and current profiles of the stator and rotor, the magnetic force and torque in the rotor bar are also affected by the presence of broken bar faults and the motor performance would deteriorate as the number of broken rotor bars increases. Simulation results based on detailed theoretical analysis are validated by the experimental results.

Experimental test and simulation results have illustrated the reason why the broken bar faults are severe and the likelihood of fault propagation to the adjacent bars. From the results in the work, one can appreciate that the broken bar position has a great impact on the motor's operation, especially on the stator current and starting torque. This further confirms the capability of the proposed numerical models which have accounted for the impact of harmonic components of air-gap flux density. Clearly, this research has also highlighted a necessity for advanced online diagnostic techniques to detect the broken bar faults since these are a common and severe type of mechanical faults to break down the induction motors in service.

However, it needs to point out that this chapter has taken use of a 2-D finite element method to analyze the induction motor's electro-magnetic, thermal, mechanical performance, which is proved to be suitable. If more complex problems are involved such as overhang region bar faults, a 3-D finite element method may be required. This is the further work of this research.

\section{Acknowledgement}

This work was supported in part by National Natural Science Foundation of China (51107022), Specialized Research Fund for the Doctoral Program of Higher Education (20102303120001), and China's Postdoctoral Science Foundation (20100480891).

\section{References}

Alberti, L. \& Bianchi, N. (2008). a Coupled Thermal-Electromagnetic Analysisfor a Rapid and Accurate Prediction of IM Performance. IEEE Transactions on Industrial Electronics, Vol. 55, No. 10, (October 2008), pp. 3575-3582, ISSN 0278-0046

Antal, M. \& Zawilak, J. (2005). Coupling Magneto-thermal Field of Induction Motor with Broken Rotor Bars. Maszyny Elektryczne, Vol.72, (2005), pp. 267-272, ISBN 83-2040335-9

Bacha, K.; Gossa, M., Capolino, G.-A. (2004). Diagnosis of Induction Motor Rotor Broken Bars. 2004 IEEE International Conference on Industrial Technology, pp.979-984, ISBN 07803-8662-0, Hammamet, Tunisia, December 8-10,2004

Bangura, J.F. \& Demerdash, N.A. (1999). Diagnosis and Characterization of Effects of Broken Bars and Connectors in Squirrel-cage Induction Motor by Time-stepping Coupled 
FE State Space Modeling Approach. IEEE Trans. EC., Vol.14, (April 1999), pp.11671175, ISSN 0885-8969

Bellini, A.; Filippetti, F., Franceschini, G., Tassoni, C., Kliman, G.B. (2001). Quantitative Evaluation of Induction Motor Broken Bars by Means of Electrical Signature Analysis. IEEE Trans on Industry Applications, Vol.37, No.5, (2001), pp. 1248-1255, ISSN 0093-9994

Bentounsi, A. \& Nicolas, A. (1988). on Line Diagnosis of Defaults on Squirrel Cage Motor Using FEM. IEEE Trans. Magnetics, Vol.34, No.5, (September 1998),Part:1, pp. 35113514, ISSN 0018-9464

Boglietti, A.; Cavagnino, A., Staton, D.A. (2005). TEFC Induction Motors Thermal Models: A Parameter Sensitivity Analysis. IEEE Trans on Industry Applications, Vol.41, No.3, (May/June 2005), pp. 756-763, ISSN 0093-9994

Casimir, R.; Bouteleux, E., Yahoui, H., Clerc, G., Henao, H., Delmotte, C., Capolino, G.-A., Rostaing, G., Rognon, J.-P., Foulon, E., Loron, L., Razik, H., Didier, G., Houdouin, G., Barakat, G., Dakyo, B., Bachir, S., Tnani, S., Champenois, G., Trigeassou, J.-C., Devanneaux, V., Dagues, B., Faucher, J.(2004). Comparison of Modeling Methods and of Diagnostic of Asynchronous Motor in Case of Defects. International Power Electronics Congress - CIEP, 9th IEEE International Power Electronics Congress Tehcnical Proceedingss, pp. 101-108, ISBN 0-7803-8790-2, Celaya, Mexico, October, 2004

Cho, K.R.; Lang, J.H., Umans, S.D. (1992). Detection of Broken Rotor Bars in Induction Motors Using State and Parameter Estimation. IEEE Transactions on Industry Applications, Vol. 28,No.3, (May/Jun 1992), pp. 702-709, ISSN 0093-9994

Costa, F.F.; de Almeida, L.A.L., Naidu, S.R., Braga-Filho, E.R., Alves, R.N.C. (2004). Improving the Signal Data Acquisition in Condition Monitoring of Electrical Machines. IEEE Trans on Instrumentation and Measurement, Vol. 53, (August 2004), pp.1015-1019, ISSN 0018-9456

Elkasabgy, N.M.; Eastham, A.R., Dawson, G.E. (1992). Detection of Broken Bars in the Cage Rotor on an Induction Machine. IEEE Trans on Industry Applications, Vol.28, No.1, (1992), pp. 165 -171, ISSN 0093-9994

Gao Jingde; Wang Xiangheng, Li Fahai. (1993). Analysis of AC Machines and Their Systems, Tsinghua University Press, ISBN 7-302-01251-2, Beijing

Kliman, G.B.; Koegl, R.A., Stein, J., Endicott, R.D., Madden, M.W. (1988). Noninvasive Detection of Broken Rotor Bars in Operating Induction Motors. IEEE Trans on Energy Conversion, Vol.3, No.4, (December 1988), pp. 873-879, ISSN 08858969

Lopez-Fdez, X.M.; Donsion, M.P., Cabanas, M.F., Melero, M.G., Rojas, C.H. (1999). Thermal performance of a 3-phase induction motor with a broken bar, SDEMPED' 99 Record, pp. 529-533, ISBN 978-0-7803-9124-6, Gijón, Spain, September 1999

Mirafzal, B. \& Demerdash, N.A.O. (2004). Induction Machine Broken-bar Fault Diagnosis Using the Rotor Magnetic Field Space-vector Orientation. IEEE Trans. Industry Applications, Vol.40, No.2, (February 2004), pp. 534-542, ISSN 0093-9994 
Mohammed, O.A.; Abed, N.Y., Ganu, S. (2006). Modeling and Characterization of Induction Motor Internal Faults Using Finite-Element and Discrete Wavelet Transforms. IEEE Trans. Magnetics, Vol.42, No.10, (October 2006), pp. 3434-3436, ISSN 0018-9464

Mueller, M.A.; Williamson, S., Flack, T.J., Atallah, K., Baholo, B., Howe, D., Mellor, P.H. (1995).Calculation of Iron Losses from Time-stepped Finite-element Model of Cage Induction Machines. IEEE Conference Publication, No.412, (September 1995), pp. 8892, ISSN 0537-9989

Ning Yuquan. (2002). Faults Detection and On-line Diagnosis Calculating Parameter in Squirrel Cage Induction Motors with Broken Bars and End Ring Connections. Proceedings of the Chinese Society for Electrical Engineering, Vol.2, No.10, (May 2002), pp. 97-103, ISSN 0258-8013

Said, M.S.N.; Benbouzid, M.E.H., Benchaib,A. (2000). Detection of Broken Bars in Induction Motors Using an Extended Kalman Filter for Rotor Resistance Sensorless Estimation. IEEE Trans on Energy Conversion, Vol.15, No.1, (March 2000), pp. 66-70, ISSN 0885-8969

Sprooten, J. \& Maun, J.-C.(2009). Influence of Saturation Level on the Effect of Broken Bars in Induction Motors Using Fundamental Electromagnetic Laws and Finite Element Simulations. IEEE Trans. Energy Conversion, Vol.24, No.3, (September 2009), pp. 557-564, ISSN 0885-8969

Staton, D.; Boglietti, A., Cavagnino, A. (2005). Solving the More Difficult Aspects of Electric Motor Thermal Analysis in Small and Medium Size Industrial Induction Motors. IEEE Trans on Energy Conversion, Vol.20, No.3, (September 2005), pp.620-628, ISSN 0885-8969

Tang Yunqiu. (1998). Electromagnetic Field in Electric Machine. Science Press, ISBN 7-03005296-X, Beijing

Walliser, R.F. \& Landy, C.F. (1994). Determination of Interbar Current Effects in the Detection of Broken Rotor Bars in Squirrel Cage Induction Motor. IEEE Trans on Energy Conversion, Vol.9, No.1, (March 1994), pp. 152-158, ISSN 0885-8969

Weili, Li; Xie Ying, Shen Jiafeng, Luo Yingli. (2007). Finite-Element Analysis of Field Distribution and Characteristic Performance of Squirrel-Cage Induction Motor With Broken Bars.IEEE Transactions on Magnetics, Vol.43, No.4, (April 2007), pp. 1537-1540, ISSN 0018-9464

W.Thomson. \& M.Fenger. (2001). Current Signature Analysis to Detect Induction Motor Faults. IEEE Industry Applications Magazine, Vol.7, No.4, (July/August 2001), pp. 2634, ISSN 0093-9994

Xie Ying. (2009). Characteristic Performance Analysis of Squirrel Cage Induction Motor with Broken Bars. IEEE Trans. Magnetics, Vol.45, No.2, (February 2004), Part:1, pp. 759766, ISSN 0018-9464

Xie Ying. (2010). Performance Evaluation and Thermal Fields Analysis of Induction Motor with Broken Rotor Bars Located at Different Relative Positions. IEEE Trans. Magnetics, Vol.46, No.5, (May 2010), pp. 1243-1250, ISSN 0018-9464 
Yan Dengjun; Liu Ruifang, Hu Mingqiang, Li Xunming. (2003). Transient Starting Performance of Squirrel Cage Induction Motor with Time-stepping FEM. Electric machines and control, Vol. 7,(July 2003), pp. 177-181, ISSN 1007-449X 


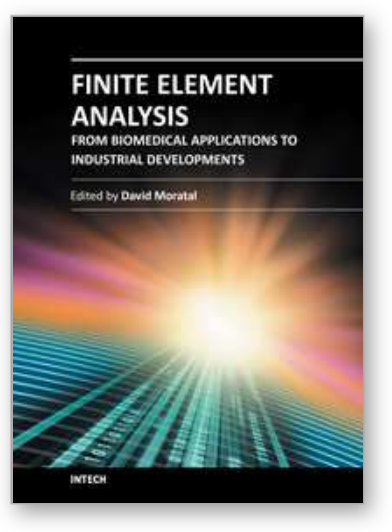

\author{
Finite Element Analysis - From Biomedical Applications to \\ Industrial Developments \\ Edited by Dr. David Moratal
}

ISBN 978-953-51-0474-2

Hard cover, 496 pages

Publisher InTech

Published online 30, March, 2012

Published in print edition March, 2012

Finite Element Analysis represents a numerical technique for finding approximate solutions to partial differential equations as well as integral equations, permitting the numerical analysis of complex structures based on their material properties. This book presents 20 different chapters in the application of Finite Elements, ranging from Biomedical Engineering to Manufacturing Industry and Industrial Developments. It has been written at a level suitable for use in a graduate course on applications of finite element modelling and analysis (mechanical, civil and biomedical engineering studies, for instance), without excluding its use by researchers or professional engineers interested in the field, seeking to gain a deeper understanding concerning Finite Element Analysis.

\title{
How to reference
}

In order to correctly reference this scholarly work, feel free to copy and paste the following:

Ying Xie (2012). Investigation of Broken Rotor Bar Faults in Three-Phase Squirrel-Cage Induction Motors, Finite Element Analysis - From Biomedical Applications to Industrial Developments, Dr. David Moratal (Ed.), ISBN: 978-953-51-0474-2, InTech, Available from: http://www.intechopen.com/books/finite-element-analysisfrom-biomedical-applications-to-industrial-developments/investigation-of-broken-rotor-bar-faults-in-threephase-squirrel-cage-induction-motors

\section{INTECH}

open science | open minds

\author{
InTech Europe \\ University Campus STeP Ri \\ Slavka Krautzeka 83/A \\ 51000 Rijeka, Croatia \\ Phone: +385 (51) 770447 \\ Fax: +385 (51) 686166 \\ www.intechopen.com
}

\author{
InTech China \\ Unit 405, Office Block, Hotel Equatorial Shanghai \\ No.65, Yan An Road (West), Shanghai, 200040, China \\ 中国上海市延安西路65号上海国际贵都大饭店办公楼 405 单元 \\ Phone: +86-21-62489820 \\ Fax: +86-21-62489821
}


(C) 2012 The Author(s). Licensee IntechOpen. This is an open access article distributed under the terms of the Creative Commons Attribution 3.0 License, which permits unrestricted use, distribution, and reproduction in any medium, provided the original work is properly cited. 